\title{
Thiamine Concentrations in Newly Hospitalized Elderly Patients with Infectious Diseases at a Community Hospital in Japan
}

\author{
Yusaku AKASHI ${ }^{1,2}$, Hiromichi SuZUKI ${ }^{1,3}$, Koji KANEMOTO ${ }^{4}$, Yumi HirosE ${ }^{5}$, \\ Keita YAMASHITA ${ }^{6}$, Takayuki YAMAMOTO ${ }^{7}$, Takamaro MIYAZAWA ${ }^{8}$, \\ Kazuhito HIROSE ${ }^{5}$, Hiroichi ISHIKAWA ${ }^{1,4}$ and Tetsuhiro MAENO ${ }^{2}$ \\ ${ }^{1}$ Department of Clinical Laboratory Medicine, ${ }^{3}$ Division of Infectious Diseases, Department of Medicine, \\ ${ }^{4}$ Department of Respiratory Medicine, ${ }^{5}$ Department of General Medicine and Primary Care, and \\ ${ }^{6}$ Department of Clinical Laboratory, Tsukuba Medical Center Hospital, Tsukuba 305-8558, Japan \\ ${ }^{2}$ Graduate School of Comprehensive Human Sciences, University of Tsukuba, Tsukuba 305-8575, Japan \\ ${ }^{7}$ Tsukuba i-Laboratory LLP, Tsukuba 305-0005, Japan \\ ${ }^{8}$ LSI Medience Corporation Central Laboratory, LSI, Tokyo, 174-8555 Japan
}

(Received December 27, 2017)

\begin{abstract}
Summary The association between advanced age and the thiamine concentration has not been conclusively determined. A recent report from Japan showed that more than half of nursing home elderly residents at an institution had a low whole-blood thiamine concentration $(<20 \mathrm{ng} / \mathrm{mL})$. Therefore, a high incidence of low thiamine concentrations among hospitalized elderly has been anticipated in the Japanese population but never investigated. We evaluated the whole thiamine concentration in newly hospitalized elderly patients ( $\geq 65 \mathrm{y}$ old) with infectious diseases. Evaluations were performed on admission and at days 6-8 of hospitalization with liquid chromatography tandem mass spectrometry (LC/MS/MS). As a result, we enrolled a total of 471 patients from September 2015 to December 2016. The median thiamine concentration was $46 \mathrm{ng} / \mathrm{mL}$ (IQR, 37-58 ng/mL). Only 7 patients (1\%) had thiamine concentrations below $20 \mathrm{ng} / \mathrm{mL}(66 \mathrm{nmol} / \mathrm{L})$ on admission. Five of these patients were bedridden and unable to eat food by themselves, and the other two patients used loop diuretics for chronic heart failure. The thiamine concentration declined in most patients $(84 \%)$ at days $6-8$ of admission, regardless of their dietary intake during hospitalization. In conclusion, a low thiamine concentration was not prevalent among newly hospitalized elderly patients with infectious diseases. However, the thiamine concentration significantly decreased during the $6-8 \mathrm{~d}$ of hospitalization.
\end{abstract}

Key Words geriatric patients, vitamin B1, thiamine deficiency, thiamin, sepsis

Thiamine (vitamin B1) is a water-soluble vitamin that is essential for energy metabolism (1). Thiamine deficiency causes beriberi $(2,3)$, including a decrease in the heart function, muscle weakness, peripheral neuropathy, and impairment of the cognitive function and leads to Wernicke-Korsakoff syndrome in severe cases (4). As the clinical diagnosis of thiamine deficiency is challenging (5), an awareness of its prevalence and the identification of patients at high risk for thiamine deficiency are essential for the prevention of these complications.

The distributions of thiamine concentration differ among geographic areas due to differences in the dietary intake of thiamine (6). In developed countries, heavy alcohol consumption (7), malignancy (8), chronic heart failure (9), and the regular use of loop diuretics (10) have been reported to be associated with low thiamine concentrations. The thiamine concentrations also decrease rapidly during serious infectious diseases in patients requiring intensive-care unit (ICU) placement or with septic shock (11). However, this association has not been validated for non-ICU patients with infectious

E-mail: yusaku-akashi@umin.ac.jp diseases.

The association between advanced age and the thiamine concentration has not been conclusively determined (12-14). Ito et al. recently found that more than half of nursing home elderly residents had a low wholeblood thiamine concentration $(<20 \mathrm{ng} / \mathrm{mL})$ as evaluated at an institution in Japan (15). A high incidence of low thiamine concentrations among hospitalized elderly patients in the Japanese population has therefore been anticipated.

In the present study, we evaluated the thiamine concentration at the time of admission in elderly patients with infectious diseases and evaluated the change in this concentration during the first week of hospitalization.

\section{MATERIALS AND METHODS}

Patients. Investigations were performed at Tsukuba Medical Center Hospital (TMCH; 453 beds, Tsukuba, Japan) from September 1, 2015, to December 31, 2016. TMCH is located next to the University of Tsukuba Hospital and plays a role as a community-based hospital with a tertiary emergency center in the Tsukuba District of Japan. 
The patient screening criteria were as follows: $\geq 65 \mathrm{y}$ of age, admitted to the Department of General Medicine and Primary Care (GM) or the Department of Respiratory Medicine (RM), and administered antimicrobial agents on admission. Patients with prior enrollment in this study, currently using thiamine-containing medications prior to hospitalization, transferred from another acute care hospital, without infectious disease (refer to Supplemental Online Materials for the definition of infectious diseases), or without available residual blood samples on admission (e.g. no blood examination performed on admission) were excluded.

The thiamine concentration was evaluated on admission for all patients who met the above criteria. The follow-up analysis of thiamine concentration was performed on the 6th-8th day of admission for the included patients unless they received any thiamine-containing medications (e.g. parenteral nutrition with thiamine supplementation), they were discharged or died before the date of the follow-up analysis, or residual blood samples were unavailable.

All clinical data, except for the thiamine concentration, were collected through a review of the medical records, nursing databases, and microbiology records. The data were examined by two physicians (YA and HS) who made decisions based on consensus. The patients in whom the diagnosis of infectious diseases could not be determined by the two physicians were further evaluated by a third investigator (KK or $\mathrm{YH}$ ).

This observational study with residual blood use was conducted according to the ethical principles laid down in the Declaration of Helsinki and was approved by the Research Ethics Review Board of Tsukuba Medical Center Hospital (approved number: 2015-006).

Data collection. The demographic data included the age, sex, body mass index, functional capacity in activities of daily living (ADL) prior to hospitalization (Katz index (16)), history of aspiration, residence, use of tube feeding or parenteral nutrition, extent of alcohol intake (heavy alcohol consumption; $>80 \mathrm{~g}$ daily), comorbidities assessed by the Charlson Comorbidity Index (CCI) (17), immunosuppressive state (18), and regular medication.

The clinical and laboratory data included the duration from symptom onset to admission, appetite change prior to admission, the daily average dietary intake from the day after admission to the follow-up analysis, albumin concentration, the presence of septic shock, inpatient death, and primary sources of infection (refer to Supplemental Online Materials for definitions). The dietary intake of the first week after admission was divided into 3 categories (low, $<15 \mathrm{kcal} / \mathrm{kg} / \mathrm{d}$; moderate, 15 to $30 \mathrm{kcal} / \mathrm{kg} / \mathrm{d}$; adequate, $\geq 30 \mathrm{kcal} / \mathrm{kg} / \mathrm{d}$ ), as determined by the required amount of energy in geriatric patients (19).

The analysis of the thiamine concentration. The blood samples were stored in a freezer at $-30^{\circ} \mathrm{C}$ within a day after being obtained, and the thiamine concentration was analyzed within a month after being assessed for its eligibility (refer to Supplemental Online Materials for effect of frozen storage on the thiamine concentration). The thiamine concentration was determined as the amount of free thiamine in whole blood. Three thiamine phosphate esters were hydrolyzed to free thiamine during the sample preparation and included in the analysis. We employed liquid chromatography tandem mass (LC/ MS/MS; Liquid chromatograph, LC-20AD, Shimadzu Medical Systems, Osaka, Japan; Mass spectrometer, API3200TM, SCIEX, Toronto, Canada) at LSI Medience Corporation Central Laboratory (Tokyo, Japan), which has replaced high-performance liquid chromatography (HPLC) in most centralized laboratories in Japan. LC/ MS/MS was performed as previously described (20), and the values have been shown to have excellent linear correlation with those obtained with HPLC and be almost equal to those obtained with HPLC (20).

Outcomes. As the primary outcome, we assessed the distribution of thiamine concentration on admission and the characteristics of patients with low thiamine concentrations. The secondary outcome was the change in thiamine concentrations on the 6th-8th day of admission.

A laboratory definition of thiamine deficiency was not established. Previous studies have regarded a whole-blood thiamine concentration below $20 \mathrm{ng} / \mathrm{mL}$ $(66 \mathrm{nmol} / \mathrm{L})$ or $30 \mathrm{ng} / \mathrm{mL}(100 \mathrm{nmol} / \mathrm{L})$ as indicative of thiamine deficiency, and the prevalence and associated factors has been investigated. In the present study, we evaluated the prevalence of a thiamine concentration below these values for comparison with previous research.

Statistical analyses. Continuous data are presented as the median value (interquartile range; IQR). Comparisons of the continuous variables were performed using the Mann-Whitney $U$ test or Wilcoxon's signed rank test (21). Fisher's exact test was used for all categorical data (22). A multivariate logistic regression analysis was conducted to determine the factors associated with a low thiamine concentration (23). Variables with a $p$ value of $<0.05$ on a univariate analysis were used to construct multivariate logistic regression models. All of the data analyses were performed using the $\mathrm{R}$ 3.3.1 software program. Statistical significance was defined as $p$ value $<0.05$.

\section{RESULTS}

\section{Patient selection}

Figure 1 depicts the patient selection process in detail. Of the 678 patients $\geq 65 \mathrm{y}$ of age who had been administered antimicrobial agents on admission, we excluded 82 for previous enrollment in the current study, 73 for lacking residual blood samples, 19 for transferring from other acute-care hospitals, 19 for not having infectious diseases, and 14 for currently using thiamine-containing medications. As a result, we finally identified 471 patients who met the criteria and had their thiamine concentration analyzed.

Of these 471 patients, 91 (19\%) received empiric thiamine supplementation after hospitalization, and 272 (58\%) underwent a follow-up analysis of the thiamine 


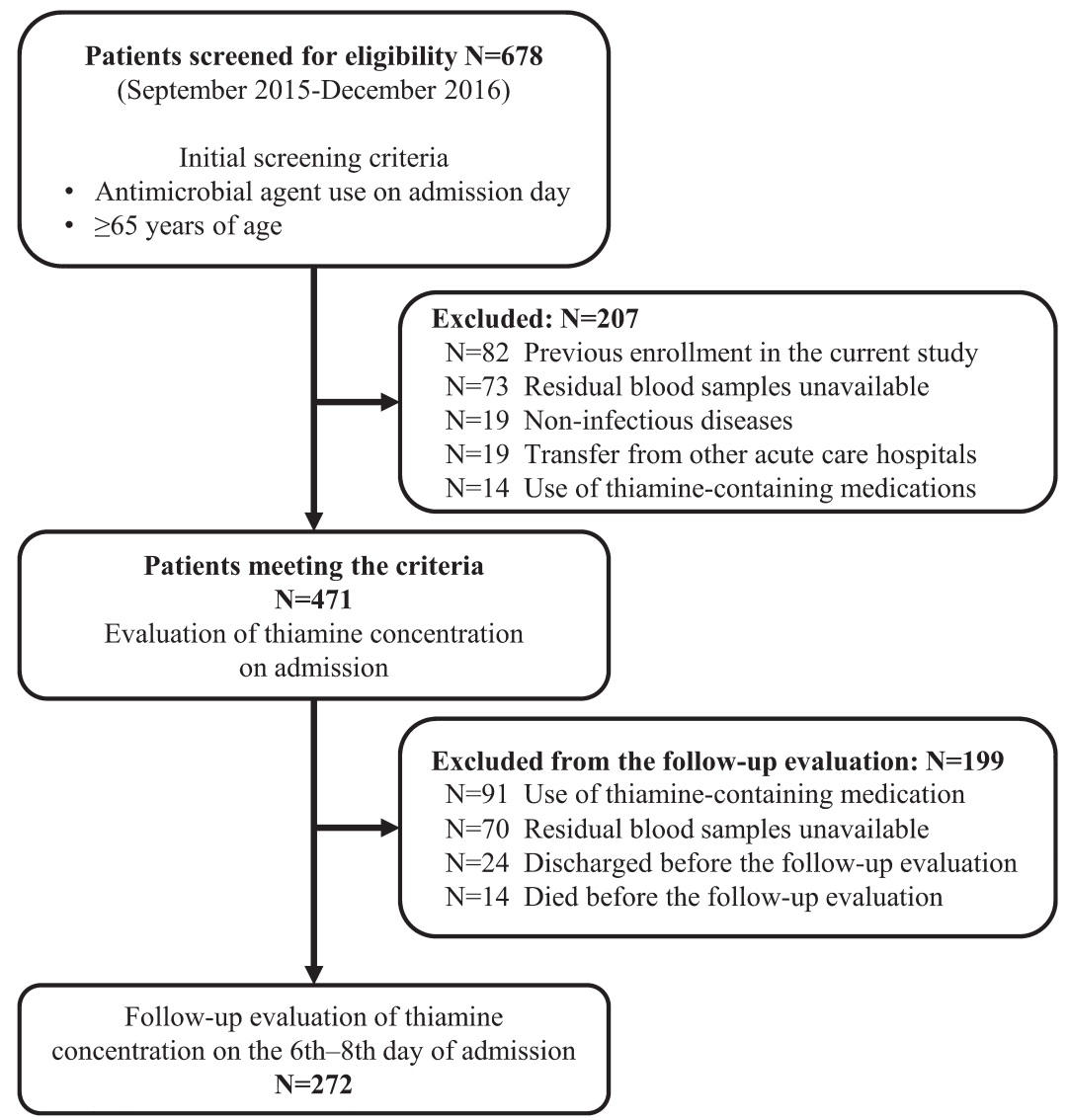

Fig. 1. Flowchart of the patient identification process.

concentration on the 6th-8th day of admission.

Thiamine concentrations on admission and clinical characteristics of patients with concentrations $<20 \mathrm{ng} / \mathrm{mL}$ or $<30 \mathrm{ng} / \mathrm{mL}$

Figure 2 shows the frequency distribution of thiamine concentrations on admission in 471 patients. The median thiamine concentration was $46 \mathrm{ng} / \mathrm{mL}$ (IQR, 37-58 ng/mL).

There were only 7 patients $(1 \%$; 3 females, 4 males) with thiamine concentrations $<20 \mathrm{ng} / \mathrm{mL}(66 \mathrm{nmol} / \mathrm{L})$ on admission, and their clinical characteristics are described in Table 1. None of these patients received parental nutrition, but six had impairment of ADL, and five were bedriden and could not eat daily meals by themselves. Two patients were taking loop diuretics for heart failure. All seven patients had comorbidities, and five had significant comorbidities (CCI score $\geq 5$ ). Six patients had a history of decreased appetites, and the duration was longer than $1 \mathrm{wk}$ in three patients. Five patients had hypoalbuminemia $(\mathrm{Alb}<3.0 \mathrm{~g} / \mathrm{dL})$ on admission.

Of the 471 patients, 45 (10\%) had thiamine concentrations $<30 \mathrm{ng} / \mathrm{mL}$ on admission. On comparing the patient groups with thiamine concentration $<30 \mathrm{ng} /$ $\mathrm{mL}$ and $\geq 30 \mathrm{ng} / \mathrm{mL}$ (Table 1 ), we found that a higher age ( 85 vs. $82 \mathrm{y}, p=0.02)$, a lower body mass index (19.3 vs. $20.9 \mathrm{~kg} / \mathrm{m}^{2}, p=0.009$ ), a lower Katz Index (ADL) (3 vs. $6, p<0.001)$, a history of aspiration ( $44 \%$ vs. $29 \%$, $p=0.04)$, a history of chronic heart failure (36\% vs.

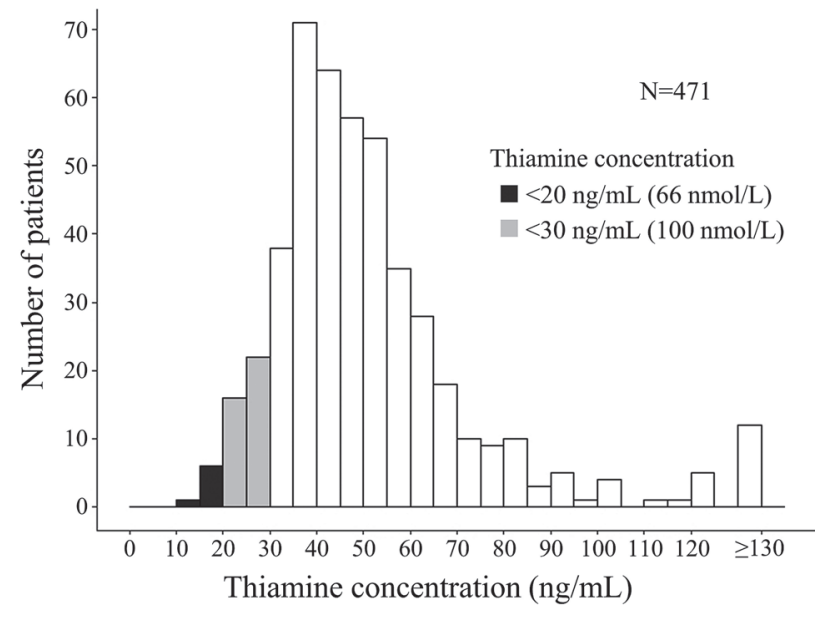

Fig. 2. Distribution of the thiamine concentration on admission.

$16 \%, p=0.004$ ), and the presence of hypoalbuminemia on admission ( $57 \%$ vs. $30 \%, p=0.001)$ were related to thiamine concentration $<30 \mathrm{ng} / \mathrm{mL}$ on admission by a univariate analysis. A multivariate logistic regression analysis using these variables showed that a history of chronic heart failure (odds ratio [OR], 3.16; 95\% confidence interval [CI], 1.28-7.61) and hypoalbuminemia (OR, 3.83; 95\% CI, 1.65-9.42) were independent factors associated with a thiamine concentration $<30 \mathrm{ng} /$ 
Table 1. Clinical characteristics of patients with low thiamine concentrations.

\begin{tabular}{|c|c|c|c|c|}
\hline & \multicolumn{3}{|c|}{ Thiamine concentrations } & \multirow{2}{*}{$p$ value* } \\
\hline & $\begin{array}{c}<20 \mathrm{ng} / \mathrm{mL} \\
(<66 \mathrm{nmol} / \mathrm{L})\end{array}$ & $\begin{array}{c}<30 \mathrm{ng} / \mathrm{mL} \\
(<100 \mathrm{nmol} / \mathrm{L})\end{array}$ & $\begin{array}{c}\geq 30 \mathrm{ng} / \mathrm{mL} \\
(\geq 100 \mathrm{nmol} / \mathrm{L})\end{array}$ & \\
\hline Number of patients & $7(1 \%)$ & $45(10 \%)$ & $426(90 \%)$ & \\
\hline Age $(y)$ & $86[84,90]$ & $85[80,89]$ & $82[75,87]$ & 0.02 \\
\hline Female gender & $3(43)$ & $14(31)$ & $172(40)$ & 0.26 \\
\hline Body mass index $\left(\mathrm{kg} / \mathrm{m}^{2}\right)$ & $17.6[17.5,18.3]$ & $19.3[16.9,21.3]$ & $20.9[18.0,23.8]$ & 0.009 \\
\hline ADL (Katz index) & $0[0,2]$ & $3[0,6]$ & $6[2,6]$ & $<0.001$ \\
\hline ADL impairment (score 0-5) & $6(86)$ & $32(71)$ & $181(42)$ & $<0.001$ \\
\hline $\begin{array}{l}\text { Bedridden without eating food } \\
\text { for themselves (score } 0 \text { ) }\end{array}$ & $5(71)$ & $14(31)$ & $68(16)$ & 0.02 \\
\hline History of aspiration & $5(71)$ & $20(44)$ & $124(29)$ & 0.04 \\
\hline Residents in long-term care facilities & $2(29)$ & $11(24)$ & $63(15)$ & 0.13 \\
\hline Tube feeding or parenteral nutrition & $0(0)$ & $0(0)$ & $13(3)$ & 0.62 \\
\hline Heavy alcohol consumption & $0(0)$ & $0(0)$ & $3(1)$ & 1.00 \\
\hline Charlson comorbidity index (CCI) & $5[4,9]$ & $2[1,3]$ & $2[1,3]$ & 0.35 \\
\hline CCI score $\geq 5$ & $5(71)$ & $8(18)$ & $44(10)$ & 0.14 \\
\hline Heart failure & $3(43)$ & $16(36)$ & $70(16)$ & 0.004 \\
\hline Dementia & $1(14)$ & $16(36)$ & $103(24)$ & 0.11 \\
\hline Diabetes mellitus & $2(29)$ & $9(20)$ & $85(20)$ & 1.00 \\
\hline Malignancy & $4(57)$ & $9(20)$ & $66(15)$ & 0.40 \\
\hline -with metastasis & $3(43)$ & $6(13)$ & $32(8)$ & 0.24 \\
\hline Immunosuppressive state & $0(0)$ & $4(9)$ & $28(7)$ & 0.53 \\
\hline Regular use of loop diuretics & $2(29)$ & $13(29)$ & $88(21)$ & 0.25 \\
\hline $\begin{array}{l}\text { Duration from symptom onset } \\
\text { to admission }(\geq 1 \mathrm{wk})\end{array}$ & $3(43)$ & $13(29)$ & $98(23)$ & 0.36 \\
\hline Decreased appetite ( $\geq 1 \mathrm{wk})$ & $3(43)$ & $6(13)$ & $30(7)$ & 0.14 \\
\hline Hypoalbuminemia (Alb <3.0 g/dL) & $5 / 7(71)$ & $24 / 42(57)$ & $125 / 410(30)$ & 0.001 \\
\hline Septic shock & $1(14)$ & $2(4)$ & $24(6)$ & 1.00 \\
\hline Inpatient death & $3(43)$ & $6(13)$ & $57(13)$ & 1.00 \\
\hline Source of infection & & & & 0.12 \\
\hline Pulmonary & $7(100)$ & $32(71)$ & $298(70)$ & \\
\hline Urinary tract & $0(0)$ & $6(13)$ & $70(16)$ & \\
\hline Skin, soft tissue, joint and bone & $0(0)$ & $6(13)$ & $19(4)$ & \\
\hline Intestine or biliary tract & $0(0)$ & $0(0)$ & $15(4)$ & \\
\hline Others & $0(0)$ & $1(2)$ & $24(6)$ & \\
\hline
\end{tabular}

Categorical data are presented as number (proportion, \%). Continuous data are presented as median [interquartile range]. ${ }^{*} p$ value $<0.05$, the comparison was performed between patients with thiamine concentration below $30 \mathrm{ng} / \mathrm{mL}$ and patients with thiamine concentration equal to or more than $30 \mathrm{ng} / \mathrm{mL}$.

$\mathrm{mL}$ on admission.

Change in thiamine concentration by the 6th-8th day of admission

Figure 3 shows the change in the thiamine concentration by the 6 th- 8 th day of admission in 272 patients. The median thiamine concentration decreased from $46 \mathrm{ng} / \mathrm{mL}(\mathrm{IQR}, 38-57 \mathrm{ng} / \mathrm{mL} ; n=272)$ to $37 \mathrm{ng} / \mathrm{mL}$ (IQR, 32-46 ng/mL) $(p<0.001)$, and the thiamine concentration had decreased in 228 patients (84\%) from admission in this analysis.

Among these 272 patients, 3 (1\%) newly had thiamine concentrations $<20 \mathrm{ng} / \mathrm{mL}$ on the 6 th-8th day of admission. All 3 had thiamine concentration between 20 and $29 \mathrm{ng} / \mathrm{mL}$ on admission and a reduced dietary intake after hospitalization. A decrease in the thiamine concentration was observed in all groups of dietary intake: a lower dietary intake group $(n=101,45$ to
$36 \mathrm{ng} / \mathrm{mL}, p<0.001)$, a moderate dietary intake group $(n=149,46$ to $37 \mathrm{ng} / \mathrm{mL}, p<0.001)$, and an adequate dietary intake group $(n=22,51$ to $47 \mathrm{ng} / \mathrm{mL}, p=0.001)$.

On the follow-up evaluations, a thiamine concentration $<30 \mathrm{ng} / \mathrm{mL}$ was observed among $49(18 \%)$ of the 272 patients, and $30(11 \%)$ newly had thiamine concentrations $<30 \mathrm{ng} / \mathrm{mL}$.

\section{DISCUSSION}

This is the first study to evaluate the thiamine concentration in newly hospitalized elderly patients with acute infectious diseases at a community hospital in Japan. In the present study, the prevalence of a thiamine concentration $<20 \mathrm{ng} / \mathrm{mL}(66 \mathrm{nmol} / \mathrm{L})$ in elderly patients with acute infectious diseases was low (1\%), and all of the patients with a thiamine concentration $<20 \mathrm{ng} /$ $\mathrm{mL}$ on admission were bedridden, unable to eat food 


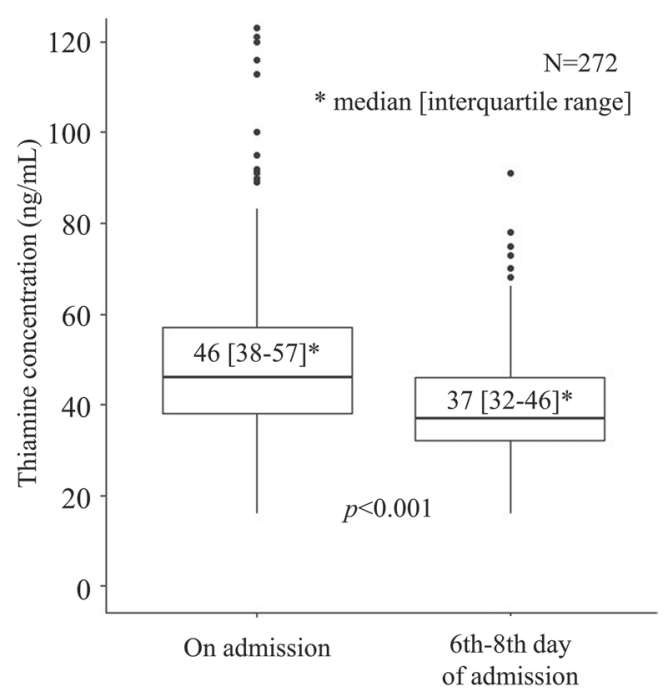

Fig. 3. Change in the thiamine concentration by $6-8 \mathrm{~d}$ after admission in 272 patients. Patients with thiamine concentration $\geq 130 \mathrm{ng} / \mathrm{mL}$ are not included.

by themselves or used loop diuretics for chronic heart failure. However, the thiamine concentration declined in most patients $(84 \%)$ a week after admission for the treatment of infectious diseases, and this decline was observed regardless of patients' dietary intake during the hospitalization.

Takeda et al. evaluated the whole-blood thiamine concentration of 869 healthy Japanese volunteers by HPLC in 2002 and found mean thiamine concentrations of $36 \pm 10 \mathrm{ng} / \mathrm{mL}$ for men $(n=524)$ and $31 \pm 8 \mathrm{ng} /$ $\mathrm{mL}$ for women $(n=345)$, with no association regarding age (24). Ito et al. observed a mean thiamine concentration of $22 \pm 9 \mathrm{ng} / \mathrm{mL}$ among elderly nursing home residents ( $n=74$, age range: $65-105 \mathrm{y}$ old) at an institution in 2012, and the thiamine concentration of 42 residents $(57 \%)$ was $<20 \mathrm{ng} / \mathrm{mL}(15)$. In the current study, the distribution of the thiamine concentration (median: $46 \mathrm{ng} / \mathrm{mL}$, IQR: 37-58 ng/mL) was not markedly different from that of healthy volunteers (24), and the results were similar even among elderly patients referred from nursing homes $(n=74$, median: $42 \mathrm{ng} /$ mL, IQR: 35-59 ng/mL). Regional differences may be associated with these findings, such as improvements in the nutritional care of elderly residents or differences in the backgrounds of the individuals (25). For example, some elderly residents are unable to have a normal oral intake, while other individuals with advanced dementia might not be appropriately referred to acute care hospitals.

Infection is known to be a risk factor of a reduced thiamine concentration due mainly to an insufficient oral intake of thiamine and increased metabolism (4, 26). Experimental studies have shown that sepsis accelerates systemic glucose turnover, which uses thiamine as a cofactor for several enzymes $(27,28)$. In addition, antimicrobial use alters gut microflora, which synthesizes thiamine (29) and may contribute to a reduced thiamine concentration during infectious disease treat- ment. Donnino et al. reported a rapid decrease in the thiamine concentration and the development of new thiamine deficiency within $72 \mathrm{~h}$ among patients with septic shock (11). In our current study, there were 10 patients with septic shock, and the thiamine concentration decreased in all of them within a week after hospitalization (median: 48 to $37 \mathrm{ng} / \mathrm{mL}, p=0.002$ ). Moreover, we revealed that the decrease occurred even among patients without septic shock in cases of nonthiamine supplementation $(n=262,46$ to $37 \mathrm{ng} / \mathrm{mL}$, $p<0.001$ ), and the development of thiamine concentration $<20 \mathrm{ng} / \mathrm{mL}$ newly occurred.

The thiamine concentration is known to be lower in patients with established risk factors than in those without such risk factors $(7-10,30)$. Concentrations were also low among patients with chronic heart failure or hypoalbuminemia in our current study, and hospitalization for infectious diseases caused thiamine depletion, even in cases of adequate food intake. These findings suggest that universal supplementation of thiamine is unnecessary for elderly patients with infectious diseases on admission, and thiamine supplementation should be considered for elderly patients with risk factors for a low thiamine concentration during inpatient care for infectious diseases.

Several limitations associated with the present study warrant mention. First, the current study was performed in a single hospital and included only patients admitted to two departments, with a substantial proportion having pulmonary infection. Furtheremore, we did not compare the thiamine concentration between the patients with infectious and non-infectious diseases. The result therefore may not be comparable to those obtained in other settings. Second, the decrease in the thiamine concentration during the follow-up period might be transient, and we were unable to determine clearly the complications of thiamine deficiency in this study. Third, the intake of each dish was not recorded; therefore, the total amount of food intake measured in this study may not accurately reflect the thiamine intake. Finally, we were unable to determine the change in the thiamine concentration for patients receiving supplementary thiamine medication. These supplementations were based on a clinical judgment of their necessity, so the decrease in the thiamine concentration might have been greater than that measured in our current study.

In conclusion, the current study showed that low thiamine concentrations were not prevalent among newly hospitalized elderly with infectious diseases. However, the thiamine concentration decreased significantly during the first week of treatment, regardless of patients' dietary intake during the hospitalization.

\section{Acknowledgments}

We are indebted to Mr. Atsushi Takeshima (LSI Medience) and the members of the Clinical Laboratory Department at TMCH and Tsukuba i-Laboratory LLP for their gracious support. 


\section{Supporting Information}

Supplemental Online Material is available on J-STAGE.

\section{REFERENCES}

1) Sriram K, Manzanares W, Joseph K. 2012. Thiamine in nutrition therapy. Nutr Clin Pract 27: 41-50.

2) Kitamura K, Yamaguchi T, Tanaka H, Hashimoto S, Yang M, Takahashi T. 1996. TPN-induced fulminant beriberi: a report on our experience and a review of the literature. Surg Today 26: 769-776.

3) Schattner A, Kedar A. 2013. An unlikely culprit-the many guises of thiamine deficiency. Am J Emerg Med 31: e635-636.

4) Sechi G, Serra A. 2007. Wernicke's encephalopathy: new clinical settings and recent advances in diagnosis and management. Lancet Neurol 6: 442-455.

5) Roman-Campos D, Cruz JS. 2014. Current aspects of thiamine deficiency on heart function. Life Sci 98: 1-5.

6) Whitfield KC, Karakochuk CD, Liu Y, McCann A, Talukder A, Kroeun H, Ward M, McNulty H, Lynd LD, Kitts DD, Li-Chan EC, McLean J, Green TJ. 2015. Poor thiamin and riboflavin status is common among women of childbearing age in rural and urban Cambodia. J Nutr 145: 628-633.

7) Baker H, Frank O, Zetterman RK, Rajan KS, ten Hove W, Leevy CM. 1975. Inability of chronic alcoholics with liver disease to use food as a source of folates, thiamin and vitamin B6. Am J Clin Nutr 28: 1377-1380.

8) Barbato M, Rodriguez PJ. 1994. Thiamine deficiency in patients admitted to a palliative care unit. Palliat Med $\mathbf{8}$ : 320-324.

9) Hanninen SA, Darling PB, Sole MJ, Barr A, Keith ME. 2006. The prevalence of thiamin deficiency in hospitalized patients with congestive heart failure. J Am Coll Cardiol 47: 354-361.

10) Seligmann H, Halkin H, Rauchfleisch S, Kaufmann N, Motro M, Vered Z, Ezra D. 1991. Thiamine deficiency in patients with congestive heart failure receiving longterm furosemide therapy: a pilot study. Am J Med 91: 151-155.

11) Donnino MW, Carney E, Cocchi MN, Barbash I, Chase M, Joyce N, Chou PP, Ngo L. 2010. Thiamine deficiency in critically ill patients with sepsis. J Crit Care 25: 576-581.

12) Lee DC, Chu J, Satz W, Silbergleit R. 2000. Low plasma thiamine levels in elder patients admitted through the emergency department. Acad Emerg Med 7: 1156-1159.

13) Leischker AH, Kolb GF, Felschen-Ludwig S. 2010. Nutritional status, chewing function and vitamin deficiency in geriatric inpatients. Eur Geriatr Med 1: 207-212.

14) O'Keeffe ST, Tormey WP, Glasgow R, Lavan JN. 1994. Thiamine deficiency in hospitalized elderly patients. Gerontology 40: 18-24.

15) Ito Y, Yamanaka K, Susaki H, Igata A. 2012. A crossinvestigation between thiamin deficiency and the physical condition of elderly people who require nursing care. J Nutr Sci Vitaminol 58: 210-216.

16) Elsawy B, Higgins KE. 2011. The geriatric assessment.
Am Fam Physician 83: 48-56.

17) Charlson ME, Pompei P, Ales KL, MacKenzie CR. 1987. A new method of classifying prognostic comorbidity in longitudinal studies: development and validation. $J$ Chronic Dis 40: 373-383.

18) Shindo Y, Ito R, Kobayashi D, Ando M, Ichikawa M, Shiraki A, Goto Y, Fukui Y, Iwaki M, Okumura J, Yamaguchi I, Yagi T, Tanikawa Y, Sugino Y, Shindoh J, Ogasawara T, Nomura F, Saka H, Yamamoto M, Taniguchi H, Suzuki R, Saito H, Kawamura T, Hasegawa Y. 2013. Risk factors for drug-resistant pathogens in community-acquired and healthcare-associated pneumonia. Am J Respir Crit Care Med 188: 985-995.

19) Sobotka L, Schneider SM, Berner YN, Cederholm T, Krznaric Z, Shenkin A, Stanga Z, Toigo G, Vandewoude M, Volkert D. 2009. ESPEN guidelines on parenteral nutrition: geriatrics. Clin Nutr 28: 461-466.

20) Miyagawa H, Gondo K, Kato M, Nakaura H, Hashizume N. 2013. Method for determining total vitamin B1 in whole blood by LC/MS/MS. Seibutsu Siryo Bunseki (J Anal Bio-Sci) 36: 327-330 (in Japanese with English abstract).

21) Bauer DF. 1972. Constructing confidence sets using rank statistics. J Am Stat Assoc 67: 687-690.

22) Sprent P. 2011. Fisher exact test. In: International Encyclopedia of Statistical Science (Lovric M, ed), p 524-525. Springer, Berlin, Heidelberg.

23) Peduzzi P, Concato J, Kemper E, Holford TR, Feinstein AR. 1996. A simulation study of the number of events per variable in logistic regression analysis. J Clin Epidemiol 49: 1373-1379.

24) Takeda A, Suyama T, Suzuki C, Imanishi M, Takeda T, Takeda R, Kitamura R, Tamai H, Kimura M. 2002. Vitamin B1 nutritional status assessed by blood vitamin B1 value of middle aged Japanese men and women. Vitamins (Japan) 76: 349-353 (in Japanese with English abstract).

25) Esther-Lee M, Berry EM. 1998. Refusal to eat in the elderly. Nutr Rev 56: 163-171.

26) Dizdar OS, Baspinar O, Kocer D, Dursun ZB, Avci D, Karakukcu C, Celik I, Gundogan K. 2016. Nutritional risk, micronutrient status and clinical outcomes: a prospective observational study in an infectious disease clinic. Nutrients 8: 124

27) Molina PE, Yousef KA, Smith RM, Tepper PG, Lang CH, Abumrad NN. 1994. Thiamin deficiency impairs endotoxin-induced increases in hepatic glucose output. Am J Clin Nutr 59: 1045-1049.

28) Lang CH, Bagby GJ, Spitzer JJ. 1984. Carbohydrate dynamics in the hypermetabolic septic rat. Metabolism 33: 959-963.

29) Said HM, Mohammed ZM. 2006. Intestinal absorption of water-soluble vitamins: an update. Curr Opin Gastroenterol 22: 140-146.

30) Gold M, Hauser RA, Chen MF. 1998. Plasma thiamine deficiency associated with Alzheimer's disease but not Parkinson's disease. Metab Brain Dis 13: 43-53. 